\title{
DIGITIZATION AND BIG DATA SYSTEM OF INTELLIGENCE MANAGEMENT IN SMART DAIRY FARMING
}

\section{Author(s):}

M. Czikkely ${ }^{1}$, D. Ivanyos ${ }^{2}$, L. Ózsvári², Cs. Fogarassy ${ }^{1}$

\section{Affiliation:}

'Szent István University, 2100 Gödöllö, Páter Károly u. 1., Hungary;

2University of Veterinary of Medicine Budapest, 1078 Budapest, István utca 2., Hungary

\section{Email address:}

czikkely.marton@szie.hu; ivanyos.dorottya@univet.hu; ozsvari.laszlo@univet.hu; fogarassy.csaba@szie.hu

Abstract: The transformation of agricultural production systems is one of the pillars of today's modern production structure. The use of digitized and big data systems and the integration of smart solutions are important for efficient business structures and environmental efficiency. This will make it possible to adapt production systems based on sustainability and economic efficiency criterias. All this can also be seen in the optimization of milk production systems, as the development of data collection systems, the systematization and analysis of the big data obtained are an important part of new business solutions. Technological development has made it possible to transform business systems using modern data collection and analysis methods. Efficient business solutions invest in technology-driven tracking of production parameters and enable flexible, immediate system development. This article provides an overview of the data collection and analysis options available through the digitization of dairy production systems, which can thus be used as a reference in subsequent system transformation and business transformation processes.

Keywords: dairy farming, circular business transformation, smart technologies, digitization, big data, intelligence system

\section{Introduction}

Smart systems that can be implemented with digitalization are an essential part of modern circular business models. In addition to value creation, which is a key part of any new business model, emphasis must be placed on operating intelligent solutions and big data systems. If we examine the economic components of value creation, the data analysis systems that can be obtained through digitization also mean the predictability and economic predictability of milk production systems. As with any agricultural production system, it is important in dairy farming how the circular business nature can be realized. Digitization and the use of smart data collection and processing systems can provide the "virtualize" side of circular business models presetnted by the ReSOLVE framework, which is often used in business transformations (Lewandowski, 2016).

Smart farming covers developments that can improve the technological background of an agricultural production system, track the economic parameters of each production cycle, and shed light on development points through big data analyse (Bronson, 2019; Wolfert et al., 2017). In modern production-economic systems, the big data obtained with intelligent solutions and remote data collection devices means a large amount of data, which accurately describes the parameters of the production system, can be easily and continuously collected, analyzed and assisted at each decision-making level to take control of productioneconomic factors (Lytos et al., 2020). Using the big data, the parameters of each production cycle can be predicted, real-time decisions can be made and business processes can be transformed in order to place each circular system element in the production system (Wolfert et al., 2017).

\section{Conceptual frameworks of smart farming technologies}

In modern smart production systems, system transformation tools based on the analysis of production data are becoming increasingly important. With the help of big data systems, production structures are becoming 
more and more data-centric, which is also facilitated by the development of computer systems and the growth of data analysis solutions. All this points towards intelligent farming (Sundmaeker et al., 2016). In intelligent production systems, not only the specific characteristics of production are taken into account, but also the traceability of real-time system events based on the collected data is considered important.

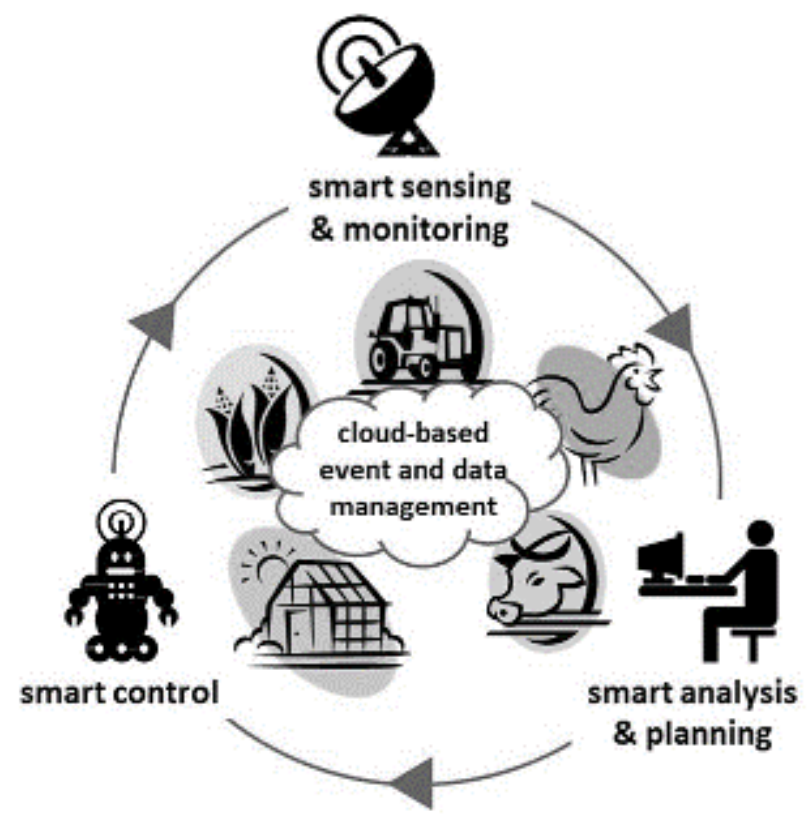

Figure 1. General overview of smart farming technologies (Wolfert et al., 2017)

In special production systems, such as dairy production systems, it is particularly important that we have the ability to act immediately with real-time data analysis solutions in the event of an unexpected accident (e.g. illness) (Wolfert et al., 2014). Figure 1 gives a general overview of the structure of intelligent production systems. The Figure also shows how a full intelligent transformation of production control systems will be possible in the future. Operating systems, data collection and analysis methods available through digitization can be effectively integrated into system transformation processes.

Big data has an important role in intelligent management systems. Different sensors are connected to each system element and to the actors involved in production (for example, farm animals in dairy production systems), which provide continuous data on pre-set and required parameters. Up-to-date and continuous data collection systems produce large amounts of data (big data), which provide feedback on the production efficiency of each system component (Wolfert et al., 2017).

There are several conceptual frameworks for the design and transformation of intelligent managment production systems. Most of these frameworks apply to value chain management as well as data-driven production strategies. All members of the production chain need to work together both vertically and horizontally to create added value, thus facilitating not only the development of intelligent production systems but also the implementation of an efficient business model (Christopher, 2005). In production systems working with a large amount of data, up-to-date continuous data provision creates a value chain connection that provides useful information during production system transformations, from data collection to decision-making. A frequently cited network management model of Lambert and Cooper (2000) builds an efficient production system structure on three interrelated pillars: network structure, business models, and management components.

In most cases, the network structure defines the participants in the production system, basically according to the special requirements of the production system. In dairy production systems, this mostly ranges from farm animals, employees to the production of the finished product. The issue of business models nowadays means the possibility of integrating circular system components, as the features of intelligent production systems available through digitalization must also be reflected in the business concept. In this case, in addition to value creation, it also means the efficient adaptation of the business model to the changing production parameters (Miller and Mork, 2013). Management components mean the tracking of the elements of the entire production system, in which big data systems are of paramount importance nowadays. As described earlier, up-to-date data collection and analysis, as well as making the necessary changes in the light 


\section{FARMING}

of the results, are all part of an intelligent management system. It is important to emphasize that big data makes it possible to monitor accurate production parameters, for example in the case of dairy production systems vital parameters related to farm animals, continuous analysis of biological, chemical and microbiological parameters of milk as a product, evaluation of measured values and non-compliant parameters (Lambert and Cooper, 2000; Miller and Mork, 2013).

Figure 2 shows an adapted framework. Big data play a role in business process planning, as can be seen in the lower layers of the Figure. Business processes are divided into three parts, these are production processes, production management, and data collection and analysis chains. Another element of the framework is provided by big data applications, which actually give the essence of intelligent production structures. The data chain and production parameters affect the network of stakeholders both individually and collectively. This framework is suitable for transforming intelligent production processes and building an efficient production business model (Lambert and Cooper, 2000; Wolfert et al., 2017).

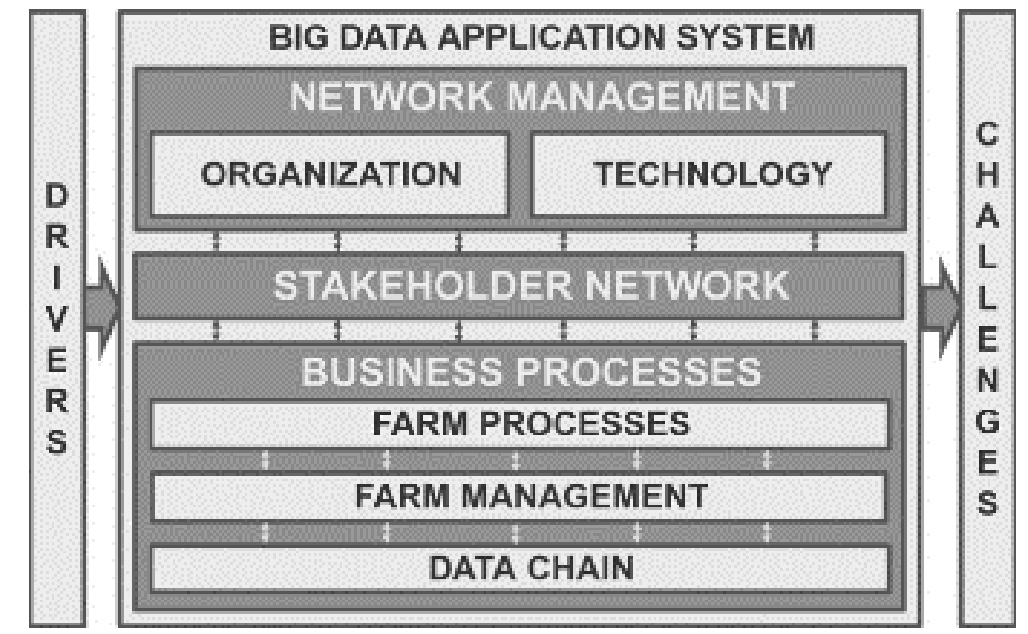

Figure 2. Conceptual framework for intelligence management of production (Based on Lambert and Cooper, 2000; adapted by Wolfert et al., 2017)

\section{Transformation of business models in focus of digitization and big data}

Current economic approaches generally follow the linear principle, the extract-product discard structure. This system does not support the environmental and sustainability aspects of our natural resources and does not visualize the material cycle (Di Maio et al., 2017). The linear economic system favors high mass production and low production costs, with the goal of obtaining the raw materials needed for production at the lowest possible cost (Blades et al., 2017; Di Maio et al., 2017). In contrast, by examining and applying the basic pillars of sustainability, i.e. the social, environmental and economic dimensions, it is possible to create the circular system that forms the basis of modern 21st century economic processes. (Michelini et al., 2017). Sustainability is a system of criteria maintained jointly by the three dimensions, ie if there is a change in one, it affects the other two. Linear economic models are not suitable for analyzing social and economic impacts in the context of consumption because they do not seek to ignore the negative impacts of production systems (Fogarassy-Kovács, 2016).

The business model adaptation of circular economic concepts typically focuses on value creation and the display of related circular system elements. Value creation basically relies on three segments: the analysis of social, economic and environmental impact factors (Blades et al., 2017). In our case, the digitization and the related efficient data collection and analysis solutions basically appear at the level of economic value creation. Figure 3 shows the three value creation segments which appear in the Business Model Canvas. This division is presented by the Triple Layer Canvas (TLC) models, which show new approaches to circular business modeling. It is important to emphasize that the three value creation segments also interact closely with each other. As shown by the Figure 3, the economic value creation is at the top, which has an impact on environmental and social value creation opportunities also. If we develop a production system from an economic (business) point of view, in this case with digitization and a big data management system, then the environmental and social factors of the total production structure also adapted to this (Joyce and Paquin, 
2016). Although the Triple Layer Canvas Model is usually compared at the levels of value creation, it should also be discussed that based on these three layers. The three layers of the Triple Layer Canvas Model are: economic layer, environmental layer and social layer. As shown on the Figure 3, these three layers are also closely (vertically) interconnected through each value creation segments. In order to carry out an effective business model transformation, it is worthwhile to prepare the layers related to the three value creation segments separately, that the detailed value creation opportunities associated with the digitization of the milk production system can be emphasized (Joyce and Paquin, 2016).

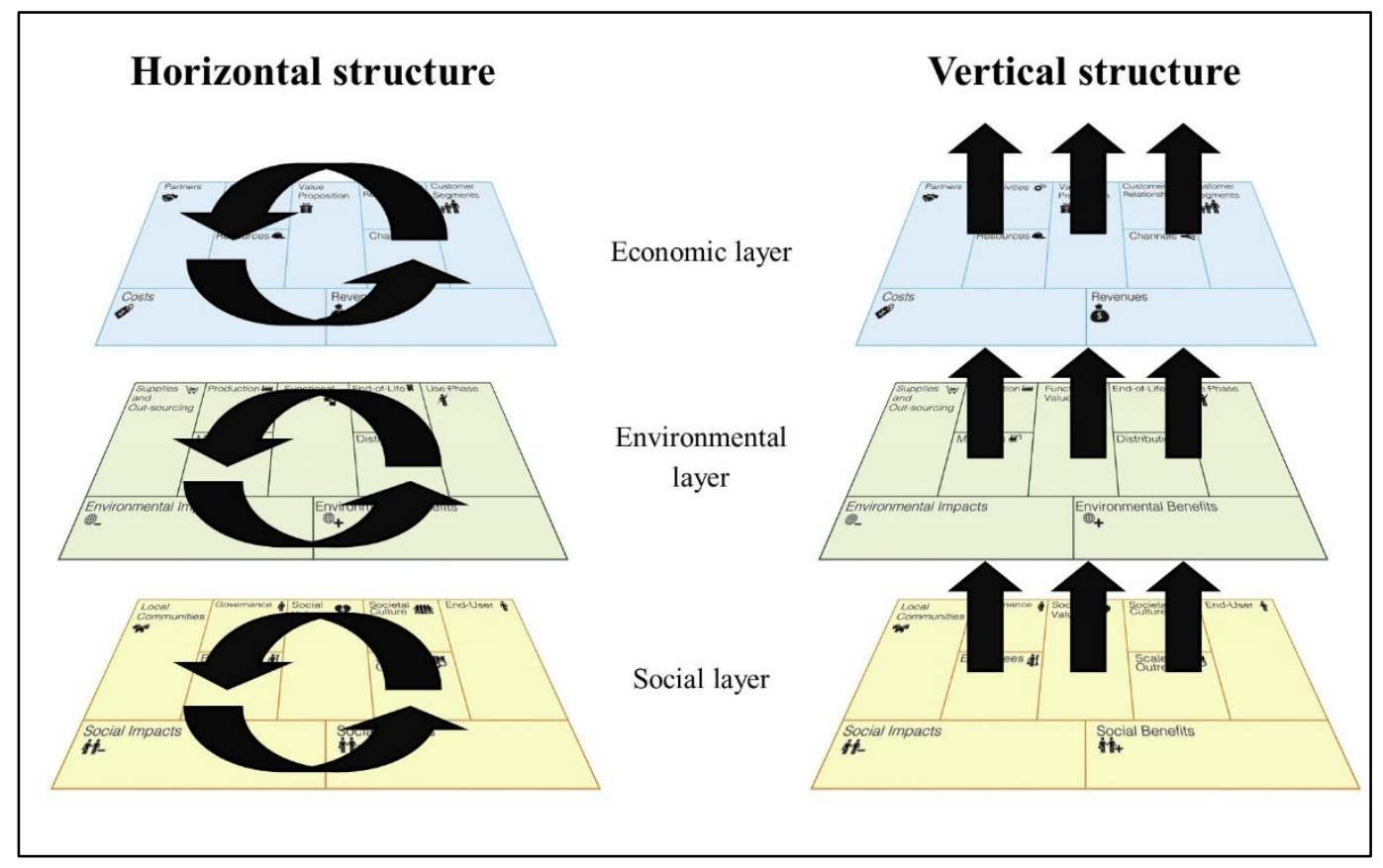

Figure 3. Value Creation by the Triple Layer Canvas Business Model (based on Joyce and Paquin, 2016)

The Triple Layer Canvas Model is an innovative solution for sustainable business models. It adds three layers to the traditional circular business model creation strategy, which are the environmental layer (typically based on the results of life cycle analysis of raw materials used in production systems and the material produced) and the social layer traditionally based on the capabilities of interested business partners (Pigneur et al., 2015). Related to these is the step of economic value creation, which vertically brings these two layers together. This enables a holistic approach to business model innovation that fosters the sustainability attitude of the Canvas Model.

The Triple Layer Canvas business model offers an opportunity to explore the horizontal and vertical relationships of production systems through value creation potential. Together with digitization and big data management systems, the value creation can be demonstrated through both the horizontal and vertical chains through the economic value creation layer (Pigneur et al., 2015).

\section{Study of transformation and digitization in a milk production system}

Recognizing economic efficiency in dairy production systems is important in several ways. On the one hand, producer systems want to achieve more income with more milk, but at the same time, providing the necessary feed for this already has an impact on cost-effectiveness. As in all production systems, it is important in milk production systems to properly assess the quality and quantity of the product. Measuring production efficiency is a particularly important segment of efficient production systems (Horvath et al., 2019). An important element of this is the efficient use of resources in both small-scale and large-scale conditions. It is important to be aware of which cows on the farm are showing how efficient they are in terms of milk production, with the most efficient feeding and health maintenance. We need to have an accurate cost assessment in order to set up an efficient milk production system. The operation of milk production systems with software data collection and analysis is definitely suitable for this, where we can work with practically artificial intelligence and computer evaluation with constantly updated data sets (Ana-Lisa, 2018). We can 
monitor the health status of the cows, their vital data, and the qualitative and quantitative parameters of the product. Biometric sensors are used to monitor the vital parameters of cows, which can be used to collect continuously measured data per cow, and by analyzing them we can save time and, above all, costs. Clinical symptoms measured on individual cows can be detected, evaluated, and immediate action is possible.

It must be seen that artificial intelligence, big data analysis systems and computer-controlled solutions improve the capital efficiency of the economy. Each cow (breeding animal) should be interpreted as a unit capital. As a result, the efficiency of the dairy farm can also be interpreted as the continuous monitoring and provision of available capital. Smart systems, by constantly monitoring the physical and vital parameters of animals (capital stock), allow for rapid and effective intervention, thus avoiding the economic disadvantage resulting from the deterioration of capital stock.

The application of savage intelligence and the necessary technological (computer) solutions is also reflected in the labor demand. It can be seen that in the case of smart milk production systems there is a lower need for labor, however, in our opinion, the need for handicrafts cannot be triggered entirely by artificial and intelligent solutions. The business success of U.S. farm systems depends heavily on approximately 3 million registered farm workers who are not seasonal but permanent players in production systems. Here, too, it can be seen that the human resource needs of the system cannot be neglected.

\section{A short overview from the Netherlands}

The following short overview presented the cooperation between the Wageningen University and the TNO Company from the Netherlands.

For many years, the dairy sector has been collecting detailed information on dairy production systems from both small and large-scale operators, and on the processes of production systems (Fogarassy et al., 2016). With this data, we can gain insight into the dairy production process, animal health, and business efficiency of the entire system along appropriate collection and analysis strategies. Each solution moves you towards optimizing business processes. The TNO Company works with Wageningen University and a number of dairy farms, such as CRV, Agrifirm or Friesland Campina (Smart, 2020). As a result, an intelligent dairy project has been built where business efficiency, scientific background and practical production side meet. TNO Company assists in the efficiency of actors in each sector, in the analysis and evaluation of big data systems, with technological solutions such as bokchain and artificial intelligence. The data (big data) of the milk production system and the results of the analysis are treated encrypted and can only be disclosed to the parties involved. This is important because it can reduce the linear elements in business models that hinder efficiency and maximize value creation. Managing big data systems in this way is important for both business partners and farmers, as it makes milk production processes more coordinated and improves the sustainability of the production system (e.g. useful life of animals, dairy ability, vital parameters) (Smart, 2020).

\section{Conclusions}

Based on the description of the study, it can be stated that artificial intelligence, intelligent system-controlled milk production systems, big data collection and analysis possibilities represent the future of modern agricultural production systems and processes. With digitalisation, a continuously and up-to-date production system can be developed, which enables immediate and effective interventions. The efficiency of business models can be increased if we successfully adapt smart systems to dairy solutions, as many European and overseas examples show that all this can be done successfully. In the dairy industry, both discrete and continuous processes can benefit from digitization. Digitization is based on a holistic approach that integrates the traditional value chain of a product, into a product and production lifecycle, from product design to manufacturing design, engineering, execution, and services. Only a fully digitized, consistent business model has the power and flexibility to accelerate processes and optimize production operations. After design and planning, the digital twins allow for virtual deployment so that all previous development steps can be effectively validated. Both the manufacturing process and packaging benefit from simulation and optimization with digital systems. Machines and production lines connected to open, cloud-based IoT operating systems provide a whole new dimension of transparency, offering additional opportunities to optimize value-added processes for customers: shorter market entry, more flexible engineering design, optimal product quality, and better plant availability and efficiency.

The aim of the study was also to shed light on these contexts as well as to show the business development opportunities obtained during the review of dairy production systems as modern agricultural production 
structures. Integrating circular system components into the production structure can be an effective solution towards creating economic value and increasing environmental and social factors as positive externalities.

In summary, the framework of the study does not allow for a detailed analysis of the smart systems associated with full digitization, but it can be stated that this is definitely the way for future milk production systems.

\section{Acknowledgement}

Special thanks to the „Európai Mezőgazdasági Vidékfejlesztési Alap: a vidéki térségekbe beruházó Európa - European Agricultural Fund for Rural Development: Europe investing in rural areas" program (Program ID: 1906020653), and to the National Research, Development and Innovation Office - NKFIH (Program ID: OTKA 131925).

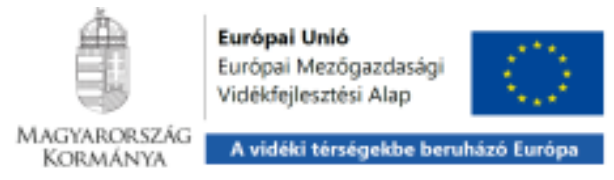

\section{References}

[1] Anna-Lisa Laca (2018) How to digitize your dairy? The Farm Journals: Milk Business. Web access: www.milkbusiness.com/article/how-to-digitize-your-dairy

[2] Ansari S. (2018). Digitizing the dairy farm: What artificial intelligence can really do. The Progressive Diary. Web: https://www.progressivedairy.com/topics/management/digitizing-the-dairy-farm-whatartificial-intelligence-can-really-do

[3] Blades L., Morgan K., Douglas R., Glovera S., De Rosa M., Cromiea T., Smyth B. (2017). Circular Biogas-Based Economy in a Rural Agricultural Setting. 1st International Conference on Sustainable Energy and Resource Use in Food Chains, ICSEF 2017, 19-20 April 2017, Berkshire, UK. Energy Procedia 123: 89-96.

[4] Bronson K. (2019). Digitization and big data in food security and sustainability. Encyclopedia of Food Security and Sustainability, 2, 582-587.

[5] Christopher, M., (2005). Logistics and Supply Chain Management: Creating Value-Adding Networks. Pearson Education.

[6] Di Maio F., Rem P.C., Balde K., Polder M. (2017). Measuring resource efficiency and circular economy: A market value approach. Resources, Conservation and Recycling 122: 163-171.

[7] Fogarassy Cs., Kovács A. (2016). The cost-benefit relations of the future environmental related developments strategies in the Hungarian energy sector. YBL Journal of Built Environment, 4 (1), 3349.

[8] Fogarassy, C., Orosz, S., Ózsvári, L. (2016) Evaluating system development options in circular economies for the milk sector - Development options for production systems in the Netherlands and Hungary. Hungarian Agricultural Engineering (30). pp. 62-74. ISSN 0864-7410

[9] Horvath, B., Khazami, N., Ymeri, P., \& Fogarassy, C. (2019). Investigating the current business model innovation trends in the biotechnology industry. Journal of Business Economics and Management, 20(1), 63-85.

[10] Joyce A., Paquin R.L. (2016). The triple layered business model canvas: A tool to design more sustainable business models. Journal of Cleaner Production, 135, 1474-1486.

[11] Lambert, D.M., Cooper, M.C. (2000). Issues in supply chain management. Indian Market Management, 29, 65-83.

[12] Lewandowski, M. (2016). Designing the business models for circular economy - towards the conceptual framework. Sustainability, 8(1), 43.

[13] Lytos A., Lagkas T., Sarigiannidis P., Zervakis M., Livanos G. (2020). Towards smart farming: Systems, frameworks and exploitation of multiple sources. Computer Networks, 172, paper ID 107147

[14] Michelini G., Moraes RN., Cunha R.N., Janain M.H., Costa A.R.O. (2017). From linear to circular economy: PSS conducting the transition. The 9th CIRP IPSS Conference: Circular Perspectives on Product/Service-Systems. Procedia CIRP 64: 2-6.

[15] Miller, H.G., Mork, P. (2013). From data to decisions: a value chain for Big Data. IT Professional, 15, $57-59$. 
[16] Pigneur Y., Joyce A., Paquin R.L. (2015). The triple layered business model canvas. Conference Proceedeings; Conference: ARTEM Organizational Creativity International Conference (Nancy).

[17] Smart dairy farming (2020): data for sustainable dairy farming sector. Case study from the Netherlands. Web: www.tno.nl

[18] Sundmaeker, H., Verdouw, C., Wolfert, S., Pérez Freire, L., (2016). Internet of food and farm 2020. In: Vermesan, O., Friess, P. (Eds.), Digitising the Industry - Internet of ThingsConnecting Physical, Digital and Virtual Worlds. River Publishers, Gistrup/Delft, 129-151.

[19] Wolfert S., Cor Verdouw L., Bogaardt M.J. (2017). Big Data in Smart Farming - a review. Agricultural systems, 157, 69-80.

[20] Wolfert, J., Sørensen, C.G., Goense, D. (2014). A Future Internet Collaboration Platform forSafe and Healthy Food from Farm to Fork, Global Conference (SRII), 2014 AnnualSRII. IEEE, San Jose, CA, USA, 266-273. 